\title{
Editorial notification
}

https://doi.org/10.1515/phon-2019-0999

Published online February 11, 2021

As Editor in Chief of Phonetica, I hereby welcome colleagues in the phonetic sciences to the journal's new home with De Gruyter publishing, effective January 1, 2021. Phonetica, the world's oldest and longest continuously running journal on research and theory in phonetics, was founded with Karger publishers in 1957 under Professor Eberhard Zwirner, who held Doctorates in both Medicine and Philosophy. The concept for the journal arose from his professional commitment to understanding language and speech disorders and the brain.

Phonetica has been a strong and important journal within the Karger publication portfolio. When the publisher recently consolidated its portfolio within the biomedical sciences, however, the decision was reached that it was timely to transfer Phonetica to a publisher with strengths in linguistics. In the name of the scientific editorial team - myself and the Associate Editors and Editorial Board members of Phonetica, who remain with the journal across the transition to De Gruyter - I extend my deepest appreciation to the executive team and staff at Karger who made the original commitment to establish the journal, and who have contributed to the journal's success over the years.

We are pleased to announce the first issue of Phonetica for 2021 published on schedule through De Gruyter, an auspicious start with our new home. We look forward to continued success of the journal as part of the Linguistics portfolio of De Gruyter, and thank the publisher and its staff who have already helped to make this transition a smooth one.

For more information on De Gruyter and submission guidelines please visit https://www.degruyter.com/phon.

Catherine T. Best

Editor in Chief of Phonetica 